\title{
Movilidades, violencia y cuidados: la experiencia de mujeres bolivianas en los territorios chilenos de la Triple-frontera Andina $^{1}$
}

\section{Mobility, Violence and Care: The Experience of Bolivian Women in the Chilean Territories of the Andean Triple-border}

\author{
Herminia Gonzalvez Torralbo² (D), Menara Guizardi \\ y Eleonora Lopez Contreras ${ }^{4}$ (1)
}

\begin{abstract}
RESUMEN
Revisamos la producción bibliográfica en las ciencias sociales sobre la experiencia femenina migrante boliviana en los territorios chilenos aledaños a la Triple-frontera Andina (entre Bolivia, Chile y Perú), enfatizando en los estudios llevados a cabo en la Región chilena de Arica y Parinacota. Partimos por situar y describir el territorio chileno de la Triple-frontera Andina. Sintetizamos, además, cómo los procesos de formación histórica de sus fronteras desempañaron un papel central en la institucionalización de patrones de violencia de género. Luego, discutimos las movilidades femeninas bolivianas y los flujos económicos las caracterizan. Sintetizamos, además, los estudios sobre la presencia boliviana aymara en los valles agrícolas de la ciudad de Arica y discutimos los hallazgos de los estudios sobre la experiencia de la violencia de género por parte de las migrantes aymara y sobre las cadenas transnacionales/transfronterizas del cuidado. En el apartado final, tejemos reflexiones sobre estos estudios.
\end{abstract}

Palabras clave: migración boliviana, mujeres, cuidados, violencia, Triple-frontera Andina

\begin{abstract}
The article reviews the social sciences' bibliography on the migrant experience of Bolivian women in the Chilean territories bordering the Andean Triple-border-Area (between Bolivia, Chile and Peru), emphasizing the studies carried out in the Chilean Region of Arica and Parinacota. We start by situating and describing the Chilean territory of the Andean Triple-border-Area. We also discuss how the processes of historical formation of its borders have played a central role in the institutionalization of patterns of gender
\end{abstract}

Agradecemos a la Agencia Nacional de Investigación y Desarrollo de Chile (ANID) que financia este estudio a través del proyecto Fondecyt 1190056: "The Boundaries of Gender Violence: Migrant Woman's Experiences in South American Border Territories" (2019-2023). Académica e Investigadora, Instituto de Investigación y Postgrado, Facultad de Derecho y Humanidades, de la Universidad Central de Chile. Correo electrónico: herminiagonzálvez@gmail.com

Investigadora asociada de la Universidad de Tarapacá (UTA). Correo electrónico: menaraguizardi@yahoo.com.br Profesora de Derecho Migratorio en la Pontificia Universidad Católica de Chile (Chile). Correo Electrónico: eleonoralopezcontreras@gmail.com 
violence. Then, we discuss the Bolivian women's mobilities and the economic flows that characterize them. We also synthesized the studies on the Bolivian Aymara presence in the agricultural valleys of the city of Arica, the findings of the studies on the experience of gender violence by the Aymara migrants, and on the transnational and cross-border chains of care. In the final section, we weave our conclusions on these studies.

Keywords: Bolivian migration, women, care, violence, Andean Triple-border-Area

El presente artículo revisa la producción bibliográfica en las ciencias sociales sobre la experiencia migrante de las mujeres bolivianas en los territorios chilenos aledaños a la Triple-frontera Andina, donde colindan Bolivia, Chile y Perú.

Las fronteras entre Bolivia y Chile atraviesan una amplia área geográfica popularmente conocida en este segundo país como el "norte grande", compuesta por tres regiones administrativas, a saber (de norte a sur): Arica y Parinacota (con capital en la ciudad de Arica), Tarapacá (con capital en Iquique) y Antofagasta (con capital en la ciudad homónima). Si bien los flujos humanos, comerciales, sociales, culturales y políticos que entrecruzan la Triple-frontera Andina se conectan con estas tres regiones, nuestros análisis se centrarán particularmente en aquellos territorios más cercanos al trifinio que la delimita, el cual, del lado chileno, se encuentra sobre la región de Arica y Parinacota (conforme detallaremos en el segundo apartado).

Este recorte analítico deviene de la constatación de que hay una amplia producción bibliográfica interdisciplinaria sobre la migración y las movilidades transfronterizas en los territorios chilenos aledaños a la Triple-frontera Andina (Guizardi, Heredia, Muñoz, Dávila \& Valdebenito, 2014; Guizardi, Valdebenito, López \& Nazal, 2017; Guizardi, Valdenenito, López \& Nazal, 2019; Leiva, 2015; Leiva, Mansilla \& Comelín, 2017; Liberona, 2015; Tapia, 2012; 2014; 2015; Tapia \& Gavilán, 2006; Zapata, Fernández, Sánchez \& Cruz, 2012). Parte relevante de estos estudios busca comprender el papel de las mujeres en la articulación de las prácticas y relaciones enmarcadas en los circuitos translocales, transnacionales y transfronterizos que entrecruzan estos territorios (Rouvière, 2014; Tapia \& Ramos, 2013). No obstante, esta producción ha sido tanto más enfática en el estudio de la migración femenina peruana en la Región de Arica y Parinacota (Guizardi \& Garcés, 2012; Guizardi et al., 2014, 2017, 2019), o de la migración boliviana en la de Tarapacá (Tapia \& Ramos, 2013, Leiva, 2015; Leiva \& Ross, 2016; Leiva et al., 2017).

Identificándose esta tendencia, nuestro recorte busca subsanar una revisión pendiente: reunir las investigaciones que dan cuenta de la presencia de migrantes bolivianas, pero buscando comprender la configuración de su experiencia en la Región de Arica y Parinacota. Pese a este enfoque, retomaremos y analizaremos la prolija producción sobre el tema en la Región de Tarapacá, buscando con esto delimitar aquellas características de la migración femenina boliviana que pueden ser reincidentes en Arica y Parinacota.

Con esto en mente, y a través de una metodología de revisión de estado-del-arte, analizamos más de 80 trabajos buscando identificar en ellos: 1) los perfiles migratorios bolivianos; 2) los nichos de inserción laboral de este colectivo; 3 ) los posibles conflictos identitarios y los procesos 
de fricción interétnica ${ }^{5}$ (vinculados al hecho de que gran parte de los y las bolivianas migrantes son indígenas aymara); 4) la especificidad de la experiencia femenina; 5) el rol de las mujeres bolivianas en la reproducción social de las familias y en las cadenas de cuidado.

La conformación histórica de esta triple-frontera, y la permanencia de imaginarios que relegan a las mujeres a una ideológica condición de inferioridad étnica (Guizardi et al., 2019) motiva parte de las indagaciones de la presente investigación. Así, nuestra revisión estuvo orientada a entender cómo y en qué medida la actual configuración del contexto (económico, social, político, cultural) de estas zonas fronterizas repercute en estos patrones de desigualdad de género enfrentados por las mujeres bolivianas. Indagamos cómo, en su vida cotidiana, ellas sortean y/o reproducen estas configuraciones. A este interrogante, se suman otros más puntuales: ¿qué actividades económicas llevan a cabo? ¿Qué estrategias simbólicas y relacionales desarrollan? ¿Qué relación hay entre sus familias, los roles de género que ellas desempeñan y las estrategias de movilidad fronteriza?

\section{El contexto y su formación histórica}

La triple-frontera Andina se sitúa sobre los territorios del Desierto de Atacama. El hito tripartito que la demarca se ubica en los valles altiplánicos (a 4.115 metros del nivel del mar) y divide los municipios de Visviri (Chile), Charaña (Bolivia) y Ancomarca (Perú), los tres constituidos a partir de asentamientos de indígenas aymara (González, 2009: 37) (ver Figura 1). Estas localidades tienen poblaciones que, sumadas, no exceden las 500 personas (González, 2009: 37).

No obstante, el intenso dinamismo de esta triple-frontera se encuentra distendido por una ruta que conecta estos pueblos con centros urbanos bolivianos, y a la costa peruana y chilena: específicamente, con las dos ciudades entre las cuales se establece la frontera chileno-peruana: Arica (Chile) (con alrededor de 200.000 habitantes), y Tacna (Perú) (ciudad en proceso de expansión económica, con una población superior a las 300.000 personas) (Guizardi et al., 2019). En este sentido, Arica y Tacna constituyen los centros urbanos que catalizan las rutas -comerciales y humanas- que entrecortan la triple-frontera Chile-Bolivia-Perú (Guizardi et al., 2017). Ellas son el epicentro de los desplazamientos y flujos entre los tres países, pese a situarse solamente entre dos de ellos (Tapia, Liberona \& Contreras, 2017). La Policía de Investigaciones de Chile (PDI), calcula que anualmente se realizan unos 6 millones de cruces entre el control fronterizo chileno (Chacalluta) y el peruano (Santa Rosa) (Pérez, Guizardi, Vicuña \& Rojas, 2015), lo que los convierte en el segundo paso internacional más transitado de Sudamérica, después de la triple-frontera Brasil-Paraguay-Argentina (Podestá, 2011: 125). Las nacionalidades más relevantes entre las personas que realizan este cruce son, en orden de importancia: la chilena, la boliviana, la colombiana, la ecuatoriana y la peruana (Pérez et al., 2015: 52).

\footnotetext{
Con "fricciones interétnicas", referimos al debate de Cardoso de Oliveira (1963: 46), para quien las sociedades nativas -los grupos étnicos amerindios- "mantienen con la sociedad envolvente (nacional o colonial) relaciones de oposición, histórica y estructuralmente demostrables. Nótese bien que no se trata de relaciones entre entidades opuestas, simplemente diferentes o exóticas, unas en relación con las otras, pero contradictorias; esto es, que la existencia de una tiende a negar la de la otra". Así, la fricción interétnica alude, precisamente a la característica básica de esta situación de contacto: “Las sociedades en oposición, en fricción, también poseen sus propias dinámicas y sus contradicciones. De ahí entenderemos la situación de contacto como una 'totalidad sincrética' o, en otras palabras, como situación de contacto entre dos poblaciones dialécticamente 'unificadas' a través de intereses diametralmente opuestos, aunque interdependientes, por paradójico que esto parezca (Cardoso de Oliveira, 1963: 46)
} 
Pero estas rutas comerciales y humanas tienen una historia que antecede la reciente tendencia a la globalización y a los flujos transfronterizos en la economía internacional (Almihat, 2007). La vida de los pueblos en el Atacama ha conllevado históricamente patrones de intensa movilidad humana y comercial entre las cuatro plataformas orográficas que componen el territorio (desde las zonas más elevadas hasta la costa del Pacífico) (Dillehay \& Núñez, 1988; Tung, 2008); y también entre ellas y los territorios situados en aquello que actualmente se denomina la Región Andina de Bolivia (donde se sitúan las ciudades de El Alto, La Paz, Oruro y Potosí).

Figura $\mathrm{N}^{\circ} 1$.

La Triple-Frontera Andina (Bolivia, Chile y Perú)

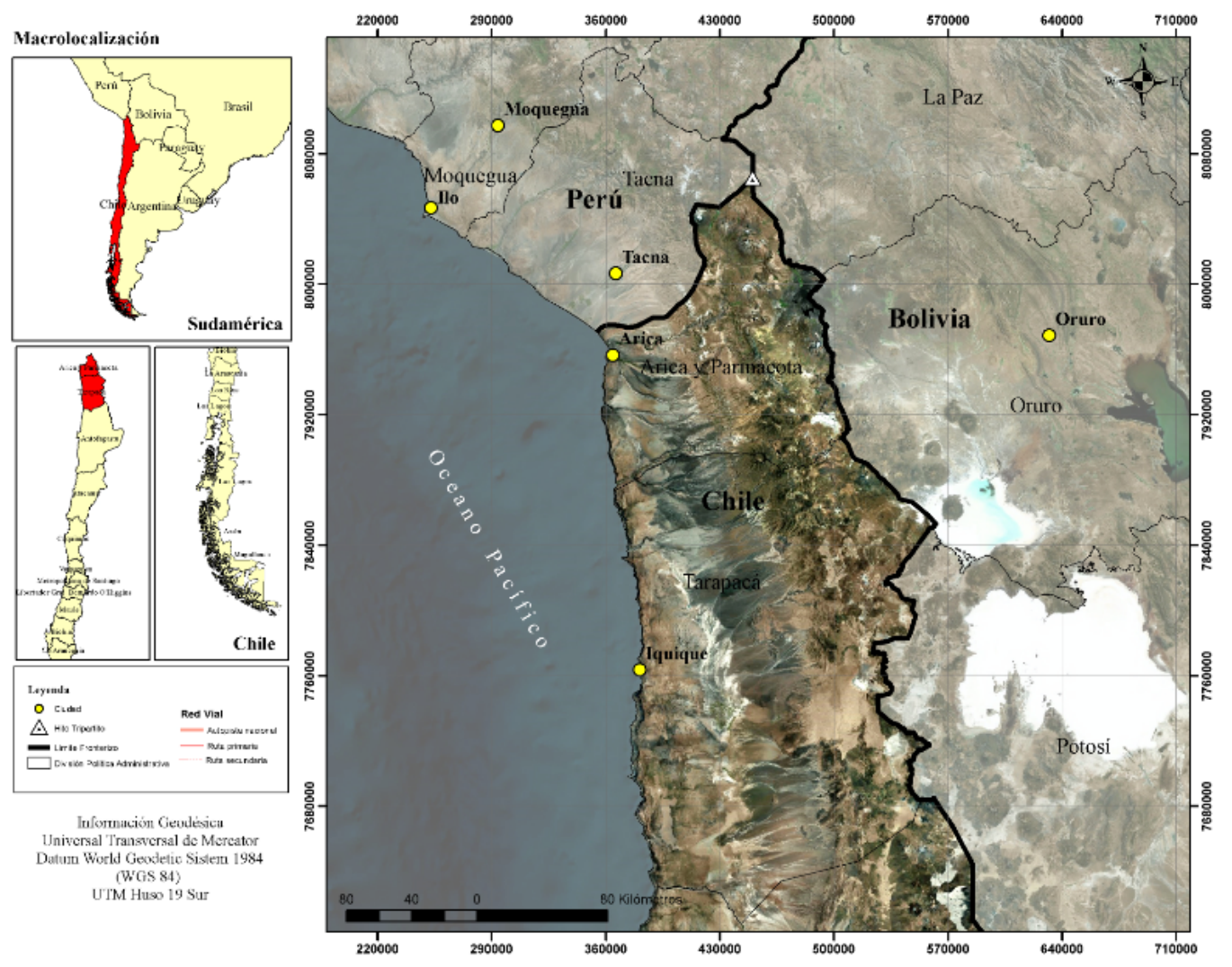

Fuente: Elaboración propia, desarrollado por Juan Jofre Cañipa, para proyecto FONDECYT 1190056.

Estos patrones son anteriores incluso a la presencia del Imperio Incaico, y fueron capitalizados por el Estado Inca (Larson, 1995) que los anexó a sus rutas comerciales que se extendían hacia 2500 kilómetros al sur de este territorio. Desde el siglo XVI, en tiempos coloniales -y, por ende, anteriores a la invención de las fronteras nacionales sobre esta región-, se activó una intensa ruta comercial entre Potosí y la costa del Pacífico, hacia la localidad de Arica (puerto de la ciudad de Tacna, sede administrativa local de la corona española) e llo (Sempat, 1995: 110); pero también hacia localidades de la actual sierra peruana (Arequipa y Cuzco). Estas rutas tenían como finalidad transportar la plata y metales preciosos a su exportación por el puerto; a la vez que permitían un intercambio de víveres y de insumos que mantenían el ciclo productivo en las minas en Potosí 
(Larson, 1995: 26; Stern, 1995: 77). Ellas han contado, además, con la participación histórica y activa de mujeres de Potosí y de los sectores andinos y altiplánicos del actual territorio boliviano en las actividades de venta urbana de los productos y su transporte a través de las redes comerciales (Mangan, 2005: 134-160)6. En este territorio, las mujeres aymara son, desde hace siglos, asociadas al comercio y caravaneo, recibiendo popularmente el nombre de matuteras.

Estas rutas, sin embargo, fueron atravesadas por la violenta conformación de las fronteras nacionales en este territorio en la segunda mitad del siglo XIX, proceso para el cual la Guerra del Pacífico (1879-1883) constituye un hito. El conflicto enfrentó a Chile (con apoyo británico) contra la Alianza entre Perú y Bolivia, y fue motivado por las disputas por los territorios de explotación de minerales (salitre y guano) en el Atacama (Vitale, 2011: 387), los cuales se encontraban situados en el entonces departamento peruano de Tarapacá y en el departamento boliviano del Litoral (cuya capital era Antofagasta). Las batallas libradas en el desierto se han caracterizado por multiplicar las pérdidas humanas, no solamente en las trincheras de guerra -en las que por lo general predominaron las atrocidades (Sater, 2007: 91)-, sino también en el difícil avance por sobre territorios áridos y debido al mal abastecimiento alimentario de las tropas. Asimismo, la guerra sedimentó el proceso de militarización del Atacama por parte de los tres países, realidad que persiste en las ciudades de Tacna y Arica -esta última es el principal enclave militar del territorio chileno (Holahan, 2005; Tapia et al., 2017)-.

Chile terminó el conflicto como "nación victoriosa", y anexó una extensión de más de 900 kilómetros en línea recta a su territorio, incorporando a su geografía tanto a Tarapacá como al Departamento del Litoral. Estas regiones constituyen los principales territorios mineros de Chile y en la actualidad respaldan el salto económico vivido por el país desde los años 1990s, con el inicio de un nuevo ciclo de expansión e internacionalización de la minería industrial (Carrasco \& Vega, 2011).

Pese a que el conflicto terminara en 1883, las fronteras entre Chile y Bolivia solo se fijaron en 1904 y los límites con Perú se establecen en 1930, fecha en la que queda formalmente dibujada y establecida la Triple-frontera Andina. Actualmente, estos límites siguen sin representar un consenso político (St John, 1994), repercutiendo reincidentemente en los debates acerca de los contornos y asertividad de las fronteras como demarcadoras de territorios con un pasado común (González, 2006; Podestá, 2011). Especialmente debido a la permanencia -en los últimos cinco siglos- de unos patrones de tránsito social que entrecruzan constantemente a los límites nacionales: las peregrinaciones religiosas, los circuitos comerciales, la formación de redes parentales distendidas entre las comunidades nativas y las dinámicas migratorias poblacionales entre las montañas, el altiplano y la costa.

Investigando la reorientación colonial del sistema de movilidades laborales en función de la extracción de plata en Potosí, Premo (2000) señala que la historiografía tradicional silenció las profundas transformaciones de género que estos cambios provocaron para las mujeres andinas. Su estudio muestra cómo ellas fueron obligadas a asumir nuevos roles y a hacerse cargo de las sobrecargas del cuidado familiar (dada la sistemática muerte de los varones en minas de Huancavelica, territorios actualmente peruanos y Potosí, en territorios actualmente bolivianos); así como también de las nuevas funciones económicas relacionadas con ello. Simultáneamente, muestra que varios nuevos liderazgos femeninos surgieron en las comunidades de la actual Triple-frontera Andina, configurando un protagonismo femenino político del todo ignorado en la historiografía precedente.

En inicios de 2007, el Estado chileno escindió la región de Tarapacá, agrupando sus territorios más septentrionales, fronterizos con Perú -las Provincias de Arica y de Parinacota- en una nueva región, la que se denominó desde entonces "Arica y Parinacota". Este desenlace territorial "significó la escisión del histórico espacio Tarapaqueño" (Valdebenito \& Guizardi, 2014: 282). 
Pero, más allá de estas prácticas sociales que, podría decirse, desafían la pretensión del establecimiento de límites euclidianos para las soberanías de los tres países, la presión estatal (militar, ideológica, identitaria y económica) por sentar la diferenciación nacional en estos espacios no ha cesado de existir desde fines del siglo XIX. En líneas generales, la victoria de Chile fundamentó la ideología de una supuesta superioridad racial, cultural, civilizatoria y religiosa de chilenos por sobre peruanos y bolivianos (Beckman, 2009; Mcevoy, 2011: 15). En este sentido, la Guerra del Pacífico ha cumplido un papel estructurante que dota la conformación de la frontera chileno-boliviana-peruana de un simbolismo sobre las asimetrías y supuestas superioridades entre las tres identidades nacionales. Para Perú, por otro lado, los bolivianos (que abandonaron el conflicto antes de su término) constituirían una nación predominantemente indígena. Pero, a diferencia del origen incaico que se asumía como parte del pasado heroico peruano (Méndez, 1995; Vich, 2010), se les comprendía a los bolivianos como genéricamente aymara, asociándose esta identidad a la ideología de una inferioridad civilizatoria. En otras palabras, la guerra terminó de sedimentar la ideología de una jerarquía entre los países, situando en este violento imaginario a Bolivia como el más incivilizado de los tres.

Se verifican, asimismo, unas implicaciones de género relacionadas a estos patrones de militarización, masculinización de la nación y violencia en el territorio de la triple-frontera. Mujeres peruanas y bolivianas, especialmente las indígenas, fueron sistemáticamente violadas por el ejército chileno a lo largo del conflicto (Sater, 2007: 92,345) y en los años inmediatamente posteriores a su término. Tanto en el caso peruano (Sater, 2007: 77-78), como en el chileno (Larraín, 2000) y boliviano (Sater, 2007: 75) las mujeres participaron en el conflicto. Tres figuras femeninas fueron cruciales para el ejército boliviano. Por un lado, las rabonas, que seguían a sus parejas militares por los campos de batalla, actuando como cocineras, enfermeras, lavanderas, amantes, camaradas e incluso cargando armas y luchando (Sater, 2007: 75). Por otro lado, estaban las vivanderas, mujeres que se desplazaban a los locales de batalla para preparar comidas y venderlas a los soldados y las contrabandistas, que conseguían mercancías (como tabaco) para abastecer a las tropas (Sater, 2007: 76-77).

La importancia femenina en estos conflictos fue borrada de la historiografía oficial en los tres países; y la guerra confirmó los contornos ideológicos de tres naciones que se narran a sí mismas a través del militarismo masculino. En Bolivia, estas concepciones siguen reproduciéndose también como una forma de acceso a la legitimidad social por parte de los hombres pobres e indígenas que, a diferencia de las mujeres, pueden servir al ejército y ganar con esto cierto estatus social (Gill, 1997). El espacio de la triple-frontera Andina sigue siendo, hasta la actualidad, uno en el que las mujeres acceden menos a derechos y sufren más violencias; tanto más si se les asocia a la condición boliviana e indígena.

\section{Movilidades femeninas y flujos económicos}

Más que constituir elementos pretéritos del escenario de la triple-frontera Andina, estos imaginarios constitutivos de las diferencias entre los tres países que allí colindan se vienen agudizando desde 1990. En especial, debido a la intensificación de la migración proveniente preferentemente de Bolivia y Perú hacia Chile (motivada por el proceso de crecimiento económico chileno y por la vuelta del país a la democracia) (Guizardi \& Garcés, 2012). 
La Triple Frontera Andina configura un espacio marcado por la condensación de las desigualdades económicas entre estos tres países (Rojas et al., 2016: 64). A pesar del crecimiento anual del Producto Interno Bruto de Bolivia (del 5,5\%) y de Perú (del 3,6\%), ambos países presentan una desventaja de poder de compra monetaria en comparación con Chile (Rojas, Amode, Koechlin \& Jiménez, 2016). El territorio chileno en el que se asienta esta triple-frontera -la región de Arica y Parinacota- posee mejores indicadores socioeconómicos que los departamentos bolivianos y peruanos colindantes, particularmente en lo que se refiere al nivel salarial (Rojas et al., 2016: 66). Esta situación explica, en parte, porqué la población se mueve predominantemente desde Perú y Bolivia hacia los territorios chilenos en esta región fronteriza ${ }^{8}$.

En dichos territorios, el porcentaje de residentes extranjeros sobre el total de la población ha bajado continuamente: del 51,9\% en 1885, al 1,8\% (su mínimo histórico) en 1992 (Tapia, 2012: 182). Pero desde 1992 hasta la actualidad, las migraciones peruanas y bolivianas han sufrido un incremento exponencial, y el norte grande chileno se ha consolidado como un polo de recepción de la migración andina (Guizardi \& Garcés, 2013). En las regiones de Tarapacá, Arica y Parinacota y Antofagasta, los migrantes llegaban a constituir, respectivamente, el 6,66\%, el 6,10 y el 3,7\% de la población local, según el censo chileno del 2002 (DEM, 2010: 16-17). Los datos del censo 2017 confirman que la Región Metropolitana de Chile (donde está ubicada la capital, Santiago) concentra la mayor cantidad, en valores absolutos, de extranjeros residentes en Chile (486.568 personas): el $65,3 \%$ del total de población migrante del país y el $7 \%$ del total de la región (que accede a 6.962.102 personas) (INE, 2018: 4). Pero las tres regiones del norte del país siguen presentando las más importantes densidades relativas de migrantes. Así, según el censo 2017, Tarapacá sería la región nacional con más densidad migratoria relativa (13,7\% de la población total), Antofagasta quedaría en segundo lugar (con 11\%), desplazando al tercer puesto a Arica y Parinacota (con $8,2 \%$ ) (INE, 2018: 4).

La afluencia migratoria peruana y boliviana en todo Chile está caracterizada por patrones de feminización (Tapia \& Ramos, 2013). No obstante, la tendencia al incremento de la feminización de estos colectivos migrantes es más acentuada en las regiones nortinas que en el centro del país (Guizardi \& Garcés, 2012). De acuerdo con la Encuesta de Caracterización Socioeconómica de Chile (CASEN, 2013: 7), entre 2009 y 2013, la composición de la población migrante internacional femenina pasó del 51,5\% al 55,1\%. No obstante, la CASEN de 2015 registró un retroceso de la participación femenina migratoria total, situando el porcentaje de mujeres migrantes en el 51,9\%. El censo 2017 registra un 50,6\% de mujeres (INE, 2018). Así, podemos contemplar una tendencia a la disminución de la participación femenina entre los colectivos migrantes, con el equilibrio demográfico entre hombres y mujeres y la retirada de la tendencia a feminización que caracterizó los flujos en inicios del siglo XXI (Martínez, 2003).

Pero el dato merece ser desglosado regionalmente. Pese a que los cómputos nacionales presenten tasas que tienden a igualar la participación porcentual de hombres y mujeres entre la población migrante en Chile, varias regiones del país presentan tasas muy relevantes de feminización migratoria. Hay un interesante efecto territorial en esta variación: las regiones más alejadas del centro del país son precisamente aquellas que presentan más elevada tasa de participación

La mayor parte de los flujos fronterizos en la Triple-frontera Andina va, en orden de importancia, 1) de Perú hacia Chile; 2) de Bolivia hacia Chile y 3) de Perú hacia Bolivia (Rojas et al., 2016, p.66). 
femenina entre los colectivos migrantes. La región del extremo norte, Arica y Parinacota, presenta la tasa del $54,9 \%$ de mujeres entre los migrantes. La región del extremo sur, Magallanes y la Antártida Chilena, presentan un $55,4 \%$ de mujeres migrantes ${ }^{9}$. Estas dos tasas son las más elevadas de todo el país (INE, 2018)

Por otro lado, la intensificación del flujo de migrantes bolivianos y peruanos hacia el norte de Chile responde, por lo menos en parte, a dos procesos de dinamización económica de la Triple-frontera Andina vinculados al comercio y a la minería.

En 1975, en el marco del gobierno militar chileno, se creó en el puerto de lquique (a unos $350 \mathrm{~km}$ de la frontera con Perú) una zona franca de impuestos (conocida como ZOFRI). La ZOFRI reconfiguró las rutas comerciales con Bolivia y Perú, moviendo no solamente el comercio lícito, sino también el ilícito, y potenciando un ingente desplazamiento protagonizado por mujeres (generalmente de origen aymara) peruanas y bolivianas que viajan para comprar mercancías en lquique, y luego siguen la ruta para distribuirlas en circuitos comerciales que llegan a englobar 3000 kilómetros y a atravesar las fronteras de Chile, Perú, Bolivia y también Argentina (Guizardi \& Garcés, 2013).

En 2002, Perú también decretó la creación de una zona franca en Tacna, a $50 \mathrm{Km}$ de la frontera con Chile. La implementación de la ZOFRA-Tacna generó, para las mujeres bolivianas involucradas en las cadenas de compra y distribución de productos importados, un circuito comercial que se desplaza desde diferentes localidades de Bolivia hasta Tacna (en Perú), entrando a Chile por Arica (donde por lo general se pernocta, debido a los relativamente bajos costes de hospedaje y alimentación), y bajando por la carretera Pan Americana hasta la Zona Franca de Iquique. De Iquique, estas mujeres bolivianas siguen con sus mercancías hacia destinos varios. Uno de ellos es la ruta que conecta con Oruro (Bolivia) (Garcés, Moraga \& Maureira 2016; Garcés \& Moraga, 2018). La otra, es la que lleva hasta Santiago (Chile) y, de ahí, al cruce hasta Argentina a través del Paso de los Libertadores (Guizardi \& Garcés, 2013). Este circuito comercial es protagonizado por mujeres bolivianas aymara que, debido a la entrada de su país al Mercado Común del Sur (Mercosur), cuentan con algunas facilidades documentales para cruzar todas estas fronteras. Este circuito ha repercutido en que tanto Tacna como Arica se hayan convertido en entrepuestos de estas mujeres, conformando entre las dos ciudades un campo social del comercio femenino boliviano que impacta fuertemente la conformación de la Triple-frontera Andina.

Al mismo tiempo, el boom de la economía minera chilena en los territorios del Atacama ha aumentado la demanda por mano de obra, estimulando la migración y los flujos humanos desde

\footnotetext{
El artículo publicado por Margarit et al. (2019) entrega información sistematizada sobre los resultados de un estudio realizado durante 2015, focalizado en la caracterización de la reciente migración extranjera en la provincia de Magallanes. Dicha sistematización precisa lo siguiente: “Según el Censo del año 2017, en la Región de Magallanes y la Antártica Chilena residian 4.714 extranjeros. De dicha cifra, el 61,2\% de los migrantes es de origen latinoamericano, principalmente argentinos, representando al 36,4\% del total de la población extranjera. Lo anterior se condice con los datos arrojados por la CASEN 2017, que registra un 3,7\% de inmigrantes residentes en la región de Magallanes. De acuerdo con las nacionalidades con mayor porcentaje, se destaca Argentina, República Dominicana, Perú y Colombia como los 4 países de origen con mayor presencia en la región (Margarit et al., 2019: 77). Asimismo, dicho estudio informa de la existencia de un fuerte componente femenino en la presencia reciente de migrantes latinoamericanos en la Región de Magallanes y la Antártica (Margarit et al. 2019: 78).

10 En el centro, la Región Metropolitana y la de Valparaíso presentan tasas del 50\% y del 48,7\%, respectivamente. Otras regiones relativamente céntricas, también presentan porcentajes femeninos inferiores al 50\% (O’Higgins, Maule, Nuble) (INE, 2018).
} 
Perú y Bolivia (Tapia, 2012). Tapia (2014: 32) y Rojas \& Silva (2016: 31-32) enfatizan que las fronteras entre Bolivia, Chile y Perú no pueden comprenderse únicamente como un destino migratorio o un lugar de tránsito. Ellas constituyen, también, un "espacio de circulación y de modos de vida binacional cada vez más frecuente" (Tapia, 2014: 32). En el caso de la migración femenina en la región, Tapia (2014: 47) menciona el cruce circular de peruanas y bolivianas para emplearse en trabajo doméstico, el comercio o para realizar contrabando "hormiga" entre Arica y Tacna. Sugiere que, a través de las estrategias de circulación, las personas provenientes de Bolivia y Perú buscan obtener beneficios con la lógica misma del cruce (diario, semanal o mensual) (Tapia, 2014: 48).

A pesar de que existan constantes conflictos sociales involucrando a la población tri-fronteriza -a causa de los flujos comerciales informales y de los problemas políticos por la disputa por las soberanías territoriales- se identifican puntos de integración relacionados a la confluencia de flujos laborales, culturales y comerciales entre los tres países. Los departamentos peruanos y bolivianos y la región chilena en que se asienta la triple-frontera están a grandes distancias de las capitales de sus respectivos países. La situacionalidad periférica que comparten con relación a los ejes decisorios de la política y de la economía de sus países incentiva a las dinámicas transfronterizas (Rojas et al., 2016: 66-68). Así, los conflictos coexisten en este espacio con la percepción, por parte de la población local, de que hay "intereses complementarios con sus vecinos fronterizos" (Rojas et al., 2016: 66)"1.

Así, la migración boliviana hacia las regiones nortinas de Chile se viene caracterizando, por un lado, por la movilización de redes sociales vinculadas a las familias y comunidades de origen y, por otro lado, por la conformación, en el marco de estas redes, de estrategias de compaginación del trabajo minero con emprendimientos comerciales autogestionados (hospederías, tiendas de pasaje hacia Bolivia, tienda de alimentación, restaurantes). Específicamente en la ciudad de Ari$\mathrm{ca}$, las redes migrantes han constituido un importante enclave laboral vinculado a las faenas en los valles agrícolas (Azapa y Lluta). Su articulación con el entramado urbano está condicionada por los comercios y transporte de productos agrícolas (estando, casi siempre, articulados por el Agro-mercado de la ciudad, que está situado en el extrarradio urbano, en la conexión con el valle de Azapa) (Guizardi et al., 2019: 151).

\section{En los Valles de Azapa y Lluta (Arica)}

La ciudad de Arica constituye uno de los principales enclaves de producción agrícola de todo el norte grande chileno (Pérez et al., 2015). Lo anterior se debe a la actividad desarrollada en dos grandes oasis productivos: los Valles de Azapa y Lluta, que se distienden por amplias extensiones bordeando la ciudad (Figura $\mathrm{N}^{\circ} 2$ ). 
Figura $\mathrm{N}^{\circ} 2$.

Valles de Azapa y Lluta en Arica (Chile)

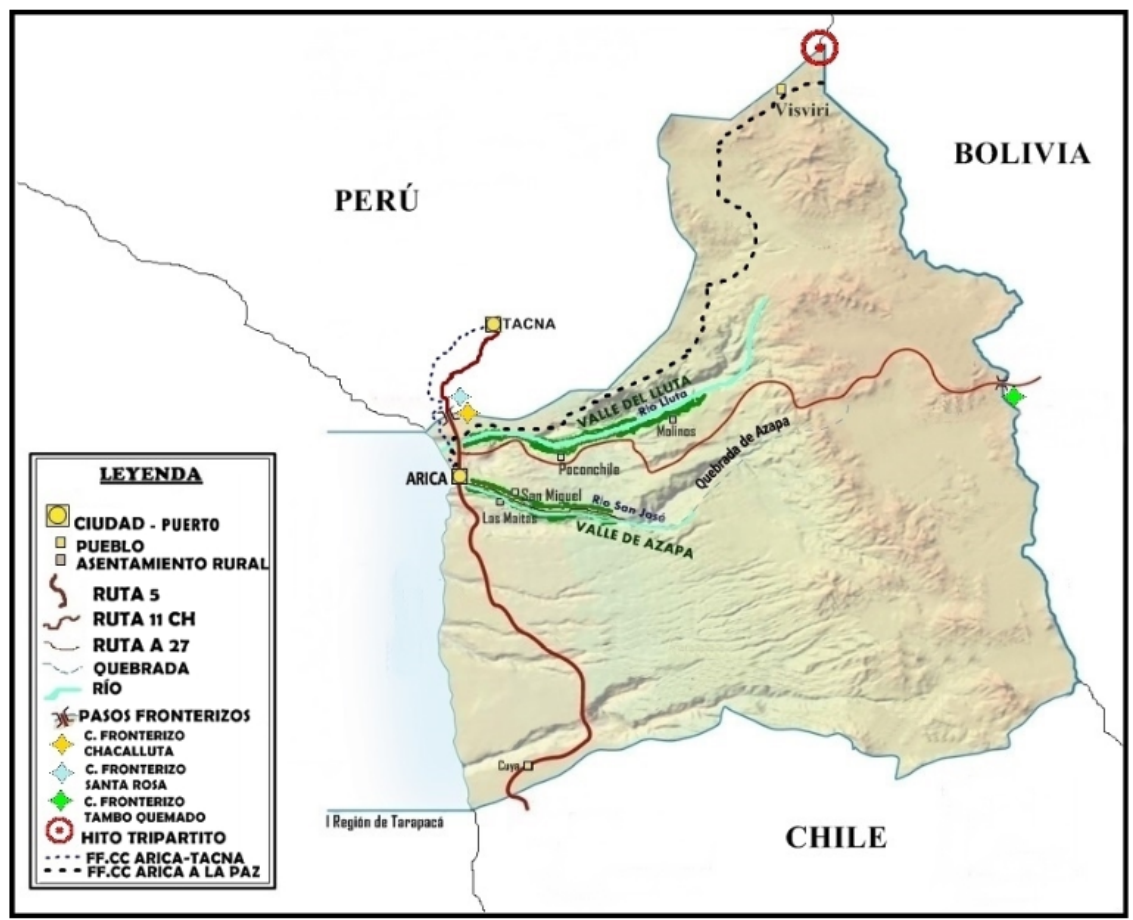

Fuente: Elaboración propia, desarrollado por Humberto Choque Rodríguez, para proyecto FONDECYT 1190056

Albó (2000), Carrasco (1998b), Chamorro (2013) y González (1998) hablan de migraciones circulares de bolivianos en los Valles de Azapa y Lluta desde los años 1960s y 1970s. En estas décadas, los aymara chilenos estaban migrando desde las localidades rurales del Atacama hacia las ciudades de la costa: muchos se pusieron a trabajar en la minería en Tarapacá o en faenas urbanas en Arica. Las tierras cultivables fueron siendo "abandonadas"; las de los Valles de Azapa y Lluta entre ellas. En los 1990s, hubo un incentivo del Estado chileno para volver a sembrar los campos. En la ocasión, muchos chilenos quisieron reactivar sus propiedades, peros sus hijos no querían asumir estas labores. Por lo mismo, los propietarios chilenos de pequeñas y medianas parcelas, mayormente de ascendencia aymara, empezaron a comunicarse con sus familias extensas en territorios bolivianos. Así habría llegado, ya para inicios de los 1990s, una nueva generación de bolivianos a sembrar los valles. A mediados de los 1990s, esta migración se intensificó, con más circulación entre Arica y localidades de origen y Bolivia y, además, con procesos de arraigo en los valles (Tapia, 2014; 2015; Tapia et al., 2017; Rojas \& Bueno, 2014).

Muchos de estos migrantes llegaron a vivir en las parcelas mismas, en casas improvisadas, de piso de tierra, sin electricidad o agua potable. Vivian, en otros casos, en galpones de almacenaje de productos y herramientas. En todas estas modalidades, los lugares de cobijo eran compartidos entre varios y varias trabajadoras y la migración se hacía, muy frecuentemente, en familia, con lo cual hombres y mujeres trabajaban juntos en la unidad familiar. Algunos de ellos y ellas venían 
por solo parte del año, por temporadas, en la medida en que los trabajos en las parcelas agrícolas demandaran más brazos. Por muchos años, varias familias iban y venían de Bolivia a los valles. Luego, algunos compraron las parcelas en las que antes trabajaban.

Empezaron, a su vez, a llamar a otros miembros de sus familias: el proceso en cadena fue llenando los dos valles. Hasta hoy, viene gente por temporadas, por año y hay muchos/as que viven permanentemente, que ya tienen hijos/as y los primeros nietos/as nacidos en Chile. A raíz de que los y las bolivianas pasaron a poder solicitar su permiso de residencia a través del acuerdo del Mercosur ${ }^{12}$, la forma como estos migrantes se relacionan con el entorno cambió. Antes, tenían miedo de traer los hijos e hijas, de mostrarse, de acudir a los sistemas y servicios públicos. Se escondían. Ahora, como muchos ya tienen papeles, andan más tranquilos e interactúan más. Es posible identificar al menos dos ejes de vulneración vividos por las mujeres bolivianas aymara en el marco de su experiencia migratoria como trabajadoras agrícolas de estos valles de Arica.

Primero, su empleo está condicionado por las redes familiares y étnicas y su posición en dichas redes apunta hacia patrones de reproducción de sistemas de desigualdad de género. Como han estudiado Rojas y Bueno (2014), las redes étnicas de la migración boliviana en los valles de Arica aseguran la inserción laboral, pero con elevados niveles de precarización e informalización; incidiendo por ello en la exclusión social tanto de hombres y mujeres bolivianas, pero más fuertemente de estas últimas. Esta exclusión social femenina se acentúa a partir de la consideración generalizada en Chile y Perú sobre la condición de etnicidad de las bolivianas. Este perverso cruce entre débil inclusión laboral-social y discriminación étnica, provoca que la experiencia de las mujeres bolivianas en estas localidades y en las rutas aledañas a la Triple-frontera Andina esté violentamente marcadas por patrones de exclusión.

En segundo lugar, las mujeres enfrentan problemas medioambientales y de salud derivados de su trabajo en la agricultura de pequeña y grande escala. La producción a larga escala agrícola en los valles ariqueños requiere el uso (intensivo y extensivo) de agrotóxicos. Megan Ryburn (2016a; 2016b), quien estudió la migración boliviana en Azapa, documentó el tremendo impacto de estos químicos en la salud de los y las trabajadoras migrantes de las tierras del valle. El trabajo de las migrantes bolivianas en la agricultura de Azapa las viene exponiendo a problemas de salud acuciantes: ellas y sus hijas/os padecen de enfermedades provocadas por la exposición a los agrotóxicos aplicados a los cultivos (como maíz, tomates, cebolla y papa). Estas experiencias de contaminación contrastan con los conocimientos y prácticas de autocuidado que las mujeres aymara perpetúan, generación tras generación, a través de una delicada relación con la medicina herbolaria.

El Acuerdo de Residencia de Mercosur es el principal instrumento que se dispone en América del Sur para promover la movilidad de los trabajadores, permitiendo a los nacionales de los Estados miembros plenos o "naciones amigas” la obtención de la residencia temporal en los paises de la subregión al que emigre, independiente de la tenencia de contratos laborales (Novick, 2010). 


\section{Migrantes aymara y violencia de género ${ }^{13}$}

Los diversos estudios antropológicos llevados a cabo del lado chileno de la frontera, sobre las relaciones entre hombres y mujeres en las familias aymara, atestiguan que "las relaciones entre los géneros se desarrollan en un contexto de poder que desfavorece a las mujeres" (Carrasco, 1998b: 88), y que "el lugar de lo masculino y su posición de poder (expresada en los términos esposo-padre) supondrían un mayor valor a estos atributos fisiológicos del cuerpo del hombre" (Gavilán, 2005: 144) $)^{14}$. Estos estudios atestiguaron, además, el incremento de las violencias machistas conyugales en el marco de familias aymara en las últimas décadas (Carrasco, 2001).

En los territorios peruanos (Rivera, 1996) y bolivianos (Meetzen, 2007), las investigadoras han sido también enfáticas al considerar, confirmando lo que expresó Segato (2013) ${ }^{15}$, que la subordinación de las mujeres aymara en la actualidad responde al "entronque entre el patriarcado colonial y racista y el patriarcado aymara, de origen precolonial" (Gargallo, 2012: 17). Consecuentemente, los estudios desarrollados con mujeres aymara de un lado y otro de las fronteras entre Chile, Perú y Bolivia, nos permiten sugerir que en sus grupos sociales también se justifica la subordinación femenina a partir de atributos afirmados como biológicos, construyéndose con ello discursos y prácticas de diferenciación entre los sexos. Así, ya fuera por influencia de la colonización/nacionalización, o por los propios procesos culturales locales, las mujeres indígenas que viven y transitan en los espacios adyacentes a la Triple-frontera Andina se encuentran corporalmente marcadas por una constitución subordinada de su identidad, tanto en lo que dice relación con sus grupos culturales de origen, como a la configuración contextual de las identidades nacionales en estos espacios.

Desde la psicología social, Zapata et al. (2012) realizaron investigaciones comparativas entre las violencias machistas vividas actualmente por mujeres aymara y no-indígenas en Arica. Encontraron la persistencia de índices expresivamente superiores entre las primeras. La meto-

\footnotetext{
Conviene traer aquí, los aportes de Segato, en relación con la consideración de la violencia de género como estructura elemental de las culturas (2010: 15). Segato (2010: 28) rechaza los planteamientos compartidos por Freud, Levi-Strauss y Lacan, cuando definen el "asesinato del padre" como el momento transicional hacia la cultura, estableciendo este acto violento como aquél que habría sedimentado la "firma" del contrato de "prohibición del incesto": pilar simbólico de la intervención social sobre la naturaleza en la especie humana (Levi-Strauss, 1969: 4243). Segato apunta, de la misma forma que hiciera Pateman (1995), que el asesinato del padre presupone una forma previa de acto violento, aquella que requiere el establecimiento apriorístico de la dominación del patriarca sobre las mujeres de su grupo. Así, el contrato fundante tiene un origen anterior al asesinato del padre en la "apropiación por la fuerza de todas las hembras de su horda por parte del macho-padre-patriarca primitivo, como el crimen que da origen a la primera Ley, la ley del estatus: la ley del género" (Segato, 2010: 28). La prohibición del incesto constituiría, entonces, un contrato entre pares, entre patriarcas, una vez establecida la ley fundante, basada en la apropiación violenta de las mujeres del grupo (Segato, 2013: 83). Esta posición asume que las desigualdades de género serían expresiones concretas que permiten la reproducción de dicha violencia patriarcal y de su espectro simbólico. Asume, además, que las redes de parentesco son, en las sociedades humanas, el entramado que, por excelencia, articula esta reproducción. Esta estructuración parental ordena, simultáneamente, los sistemas de intercambio, las redes de alianza y el tipo de reciprocidad a que diferentes grupos adhieren. Así, el parentesco y los intercambios económicos estarían vinculados a un sistema de distinción que reproduce la dominación masculina. La violencia de género sería, doblemente, el acto fundante y el mecanismo central de reproducción de esta estructuración.

Véase, además, Gavilán (2002) y Carrasco \& Gavilán (2009; 2014).

15 Segato (2013: 86), analizando el impacto de la introducción de la jerarquización público-privado colonial sobre la organización social de los grupos nativos en Sudamérica, asume que esta transformación implica para estos grupos el paso de un patriarcado de baja intensidad (en el cual el espacio doméstico era dotado de poder político y decisorio), a un patriarcado de alta intensidad que, al mismo tiempo, condena el hombre nativo a una masculinidad prototípicamente inferior a la del colonizador. Es decir: "la colonización trae consigo una pérdida radical del poder político de las mujeres, allí donde existía, mientras los colonizadores negociaron con ciertas estructuras masculinas o las inventaron, con el fin de lograr aliados" (Gautier, 2005: 718 en Segato, 2013: 86)
} 
dología llevada a cabo en el estudio se estructuró a partir de la aplicación del Index of Spouse Abuse (ISA) [Índice de Abuso Conyugal] y del Woman Abuses Screening Tool (WAST) [Herramienta Escalar de Detección de Abuso a la Mujer] a 400 mujeres. Entre ellas, 202 se declaraban no-indígenas y 198 se declaraban aymara (entre estas últimas muchas eran migrantes de origen boliviano). Todas estaban radicadas en la región de Arica y Parinacota en el momento en que participaron del estudio.

Los resultados evidenciaron mayores índices de violencia no-física en las relaciones de pareja de las mujeres sin ascendencia indígena; a la vez que apuntaron a un más elevado índice de violencias físicas entre las mujeres con ascendencia aymara (Zapata et al., 2012: 171). Las autoras establecen una relación entre la cotidianeidad de las violencias físicas hacia mujeres aymara y la distribución del trabajo doméstico en el marco de los vínculos patrimoniales étnicos, denominados Chacha-Warmi.

Dichos vínculos articulan la reproducción social, cultural y económica de la unidad familiar estableciendo la lógica de división sexual de los trabajos y de los derechos y deberes de cada género (Zapata et al., 2012: 168). Parte de los valores que sostienen estos vínculos establecen que la posición social -masculina y femenina- se estipula, entre otras cosas, por el prestigio de poseer una familia numerosa y estable. Pero, según explicitan, la obligación de procrear y reproducir a familias numerosas tiene un impacto más fuerte sobre las mujeres migrantes aymara, dado que determinan una sobrecarga de trabajo doméstico. Lo anterior se explica por la sustentabilidad de una asimetría en los roles de género en lo que concierne a la atención de niños/as y personas mayores, así como de los cuidados domésticos. De acuerdo con las autoras, dicha estructura expone a las mujeres aymara a mayores episodios de violencia precisamente porque enmarcan y naturalizan situaciones de abuso de poder y vulnerabilidad (Zapata et al., 2012: 168).

Sus hallazgos apuntan, consecuentemente, a que la institucionalización de la subordinación de las aymara en estos espacios constituye un hecho social presente, que marca la frontera, pero que tiene un impacto diferenciado (tanto más agudo) en las mujeres.

\section{Cadenas transfronterizas del cuidado}

El concepto de cuidados es polisémico, respondiendo a las diversas expresiones cotidianas en las cuales esta práctica puede manifestarse. Alude a los cuidados remunerados y no remunerados (con o sin contrato), que se realizan dentro o fuera de la casa, en un país o entre varios, desbordando límites: geográficos (distancia/proximidad geográfica), esferas de acción (público/privado), relacionales (biología/elección), morales (interés personal/altruismo), físicos (dependencia autonomía) y temporales (tiempo de vida/tiempo de trabajo), por mencionar algunos (Gonzálvez, 2016; Gonzálvez \& Acosta, 2015). Todas estas actividades, asignadas cultural e históricamente a las mujeres y naturalizadas en ellas, hacen que la reproducción de la vida sea posible. El problema es cuando esta naturalización desencadena desventajas para ellas, las cuales se expresan de formas diversas, dependiendo de las múltiples categorías de diferenciación social que se intersectan en sus experiencias femeninas. Entre ellas, la condición migratoria, la clase social, la etnia, el género, el parentesco, o el territorio. 
Actualmente, los cuidados circulan atravesando las fronteras a través de cadenas de mujeres. Muchas de ellas se encuentran emparentadas entre sí, dándole expresión a una forma de trabajo de cuidado a la distancia cuyas prácticas entremezclan múltiples tareas que requieren una gestión constante de tiempo, espacios y saberes (Gregorio \& Gonzálvez, 2012; Gonzálvez \& Acosta, 2015). De esta forma, los acuerdos y arreglos de cuidado que sostienen el hogar se reproducen en un contexto transnacional o transfronterizo desencadenando lo que Hochschild (2001) denominó "las cadenas globales de cuidado".

Los estudios sobre el tema desarrollados en territorios fronterizos latinoamericanos apuntan a que la configuración de una desigualdad de género en la distribución de los trabajos del cuidado y de reproducción social de las familias, en los distintos lados de las fronteras nacionales, articula formas específicas de inserción femenina que conectan a las mujeres que migran, cruzan la frontera o se desplazan circularmente en una cadena de transferencia de las sobrecargas del cuidado (Mattingly, 2001: 371; Pisani \& Yoskowitz, 2002: 578; Leiva et al., 2017: 23). Estos estudios dejan al descubierto, entonces, que la desigualdad -entre la obligación de cuidar y la falta de apoyos a los que derivar estas responsabilidades-empuja a las mujeres a complejas cadenas de precarización laboral y constituyen, asimismo, una desprotección, dado que ellas están del todo descubiertas del derecho de recibir cuidados (Kovic, Kelly \& Melgar, 2006: 77; Woo, 2004: 54).

Aun se carece de análisis específicos sobre la relación entre sobrecarga migrante femenina boliviana y los cuidados realizados específicamente en la Región de Arica y Parinacota. No obstante, encontramos estudios pioneros desarrollados en diferentes regiones chilenas (Martínez \& Soffia, 2013; Correa \& Vidal, 2013), y, más particularmente, en la región contigua al sur, Tarapacá (Leiva \& Ross, 2016; Leiva \& Comelin, 2017; Leiva et al., 2017; Ramos \& Urbina, 2012; Tapia \& Ramos, 2013; Tapia \& Chacón, 2016). Sobre estos últimos nos centraremos a continuación, Considerando que ellos pueden darnos luces sobre cómo pensar la problemática de la sobrecarga de género, los cuidados y la movilidad femenina boliviana en Arica y Parinacota.

El proceso de inserción de los migrantes en lquique, capital de la Región de Tarapacá, está dado por una multiplicidad de factores entre los que destacan principalmente las redes migratorias y circulares entre las localidades de origen y destino. Tapia \& Ramos (2013) han estudiado la acción de los servicios religiosos como la Pastoral de Migraciones como institución de acogida y apoyo en este proceso de inserción de mujeres bolivianas en Iquique. Las condiciones de cercanía que posee Tarapacá con respecto a Bolivia les permiten a las mujeres cierta flexibilidad en la generación de estrategias para la reproducción social de sus familias y de su propia experiencia migrante mediante la circularidad entre territorios. El retorno circular al país de origen se mantiene como una opción plausible. De la misma forma, esta flexibilidad está apoyada por la condición más accesible a los trabajos por parte de los migrantes, ya sea por el carácter de estos (precarios), o por las redes transnacionales/transfronterizas que los condicionan (Tapia \& Ramos, 2013). En Tarapacá, las redes migrantes permiten la articulación entre las mujeres migrantes y un mercado laboral concreto: cuidados y servicios domésticos (Tapia \& Ramos, 2013: 248). Más específicamente, la Pastoral Migratoria en Iquique -coordinada por el Instituto Católico Chileno de Migración (INCAMI), a cargo de la congregación católica de los Scalabrinianos-, apoya a mujeres bolivianas que posteriormente se dedicarán al trabajo de cuidado. Lo hacen a través de ofrecerles varios recursos. Entre ellos, una casa de acogida, asesoría social y jurídica, servicio de acompañamiento, almuerzo y también se les ofrece una bolsa de trabajo (Leiva et al., 2017: 21). 
Analizando precisamente estos patrones de migración circular fronteriza en Tarapacá, Leiva \& Ross (2016), Leiva \& Comelin (2017) y Leiva et al. (2017) investigan sobre la experiencia de migrantes bolivianas en el trabajo doméstico y en los servicios del cuidado en esta región. Ponen el foco no sólo en las experiencias asociadas a la migración circular, entre Chile y Bolivia, sino que también situan las trayectorias y condiciones laborales de las trabajadoras domésticas bolivianas en la ciudad de lquique. Estos estudios, nos muestran, a partir de entrevistas cualitativas en profundidad, que estas migrantes - provenientes mayormente de las localidades bolivianas de La Paz, Cochabamba, Oruro y El Alto- desarrollan una migración circular ${ }^{16}$ que tiene una duración máxima de tres meses en Chile, sin buscar establecerse en el país. Lo anterior debido a las responsabilidades de cuidado y de reproducción social de sus propias familias en el lado boliviano de la frontera.

Este patrón circular determina, por un lado, su discontinuidad laboral y, por otro, expone a las migrantes a experiencias laborales caracterizadas por diversos tipos de abuso. Entre ellos, se verifica, por ejemplo, el no pago o reducción del sueldo sin previo aviso, las jornadas que exceden el máximo de horas diarias estipuladas legalmente, el maltrato y la violencia (verbal o incluso física) por parte sus empleadores. Se registran, además, las amenazas cursadas por los niños/as a los que estas trabajadoras cuidan (Leiva \& Ross, 2016: 60-63). Consecuentemente, la circularidad laboral implica costos económicos de largo plazo para las migrantes (inhabilita acceso a jubilación, vacaciones, licencia de salud), a la vez que acarrea fuertes consecuencias emocionales. En síntesis: la sobrecarga de cuidados y tareas reproductivas del lado boliviano de la frontera las expone a situación de sobrecarga en el trabajo de cuidados remunerado en territorios chilenos.

Por su parte, el trabajo de Comelin \& Leiva (2017) se centra en la conformación de las cadenas globales de cuidado a partir de la articulación de dos crisis: la de los cuidados, en Chile, y la económica, en Bolivia. Todo ello en el contexto del marco regulatorio facilitado por el acuerdo de Mercosur, cuya normativa posibilita que la población de origen boliviano ingrese de forma transitoria a Chile debido a procesos específicos de circulación permanente entre el país de origen y de destino (Comelin \& Leiva, 2017: 203).

Estos trabajos nos ofrecen luces respecto de la importancia de analizar los cuidados como una categoría de análisis social y política centrales para entender los procesos de movilidad transnacional y transfronteriza en la Triple Frontera Andina. No obstante, todavía son escasos los estudios que se centran en examinar cómo los cuidados producen, reproducen y sostienen vida transfronteriza en la Región de Arica y Parinacota.

\section{Consideraciones finales}

A través de la presente revisión bibliográfica identificamos las distintas prácticas de movilidad protagonizadas por las comunidades aymara bolivianas en los territorios chilenos de la Triple-frontera Andina, prestando especial atención a las prácticas femeninas. Vimos que muchas de estas anteceden al establecimiento de las fronteras nacionales entre Chile, Perú y Bolivia.

Las autoras Leiva \& Comelin señalan que no existe una definición consensuada de migración circular, a partir de lo cual, ellas la definen como "un movimiento que se produce repetidamente, entre el país de origen y el de destino" (2017: 194). 
Con relación al entrecruzamiento de prácticas precoloniales, coloniales y nacionalistas -con expresiones familiares, culturales y económicas- que encuentran una historia común en el espacio de la Triple Frontera Andina, la literatura ilumina dos consideraciones centrales. Primero, se observa que la vigencia de prácticas cotidianas que reproducen el rol de las mujeres aymara bolivianas desde la desigualdad de género, la sobrecarga familiar y la encarnación de una identidad subalterna (producto de imaginarios coloniales y de los conflictos bélicos entre dichos países). Segundo, el militarismo masculino configura ha impactado (y sigue impactando) a las relaciones de subalternidad de las mujeres bolivianas en la Triple Frontera Andina.

Con relación a la inserción de las mujeres bolivianas actualmente en el lado chileno de la frontera, los estudios concluyen la persistencia de las desigualdades de género. Estas desigualdades son visibles, por ejemplo, en la inserción laboral de las migrantes. En este ámbito, la experiencia femenina boliviana sigue impactada por los imaginarios sociales ahincados históricamente. Es decir, la vinculación de la identidad boliviana a la subalternidad étnica y nacional con relación a la población chilena y peruana (re)produce, para las bolivianas, una encrucijada entre precariedad laboral, débil inclusión social y discriminación étnica.

Aunado a los elementos anteriores, la coexistencia de un patriarcado precolonial y colonial aymara se articula en la constitución de los mandatos de género y la división sexual del trabajo desde los cuales las mujeres bolivianas de esta etnia enfrentan una suma de experiencias de subordinación y desigualdad. Esta suma de experiencias interconecta su condición de mujer, indígena aymara y boliviana.

Como diversos autores/as han explicitado, en las fronteras latinoamericanas, las cadenas de cuidados se constituyen como una transferencia de las sobrecargas entre mujeres (Kovic et al., 2006; Woo, 2004). Estos estudios también coinciden en considerar que las fronteras constituyen un locus de imbricación y condensación de múltiples desigualdades (étnicas, género, económicas) (Guizardi et al., 2019). Esta condensación sería visible tanto en las labores remuneradas fuera del hogar, como en la sobrecarga familiar de las labores de cuidados naturalizadas en las mujeres.

Por lo anterior, se constituye un descuido redundante desconocer que en las mujeres bolivianas que habitan la zona de la Triple Frontera Andina, los cuidados son una forma fundamental de sostén y reproducción de sus vidas transfronterizas. La cercanía entre Bolivia y Chile, permite la inserción laboral de estas mujeres en el trabajo doméstico y de cuidados, pero también posibilita su precarización y vulnerabilidad laboral (que no deja de estar impactada por su condición de subalternidad étnica y nacional).

Por todo lo mencionado, por un lado, identificamos la necesidad de seguir investigando respecto de estas cadenas globales de cuidado (transnacionales y transfronterizas) protagonizadas por mujeres migrantes bolivianas en general, y aquellas que habitan la Región de Arica y Parinacota, en particular. Consideramos que estos nuevos estudios serían favorecidos por una perspectiva situada desde la consideración de sus trayectorias biográficas y del conocimiento histórico de los territorios en los que ellas habitan. Por otro lado, nos urge pensar el cuidado incorporando el enfoque de la interseccionalidad, para, desde allí, "colocar al cuidado en su verdadera dimensión estructural de sostén y garante del bienestar humano" (Ferro, 2019: 138). 


\section{Referencias}

ALBÓ, X. Aymaras entre Bolivia, Perú y Chile. Estudios Atacameños, San Pedro de Atacama, 2000, Vol. 19, p. 43-74. https://doi.org/10.22199/S07181043.2000.0019.00003

AMILHAT SZARY, A-L. Are Borders More Easily Crossed Today? The Paradox of Contemporary Trans-Border Mobility in the Andes. Geopolitics, 2007, Vol. 12, № 1, p. 1-18. https://doi. org/10.1080/14650040601031065

BECKMAN, E. The creolization of imperial reason: Chilean state racism in the war of the Pacific. Journal of Latin American Cultural Studies, Cambridge, 2009, Vol. 1, No 1, p.73-90. https://doi. org/10.1080/13569320902819786

CARDOSO DE OLIVEIRA, R. Aculturación y fricción interétnica. Revista América Latina, 1963, Vol. 6, p. 33-46.

CARRASCO, A.M. Constitución de género y ciclo vital entre los aymarás contemporáneos del Norte de Chile. Chungará, 1998a, Vol. 30, №1, p. 87-103. http://dx.doi.org/10.4067/S071773561998000100007

CARRASCO, A.M. Mujeres aymaras e inserción laboral. Revista de Ciencias Sociales, Iquique, 1998b, Vol. 8, p. 83-96. http://www.revistacienciasociales.cl/ojs/index.php/publicacion/article/ view/55

CARRASCO, A.M. Violencia conyugal entre los aymaras del altiplano chileno: Antecedentes para comprender las relaciones de género en el matrimonio. Revista de Ciencias Sociales Universidad J. Santos Ossa, 2001, №3, p. 85-96.

CARRASCO, A. M \& GAVILÁN, V. Representaciones del cuerpo, sexo y género entre los aymara del norte de Chile. Chungará, Arica, 2009. Vol. 41, No 1, p. 83-100. http://dx.doi.org/10.4067/S071773562009000100006

CARRASCO, A.M. \& GAVILÁN, V. Significados y prácticas de la sexualidad en tres generaciones de mujeres aymara del norte de Chile. Interciencia, 2014, Vol. 39, No 7, p. 468-475. http://dx.doi. org/10.4067/S0717-73562016005000036.

CARRASCO, C \& VEGA, P. Una aproximación a las condiciones de trabajo en la Gran Minería de Altura. Santiago: Cuaderno de Investigación N. 40. Gobierno de Chile. Dirección del Trabajo, Departamento de Estudios, 2011.

CHAMORRO, A. Carnaval Andino en la ciudad de Arica: Performance en la frontera norte chilena. Estudios atacameños, San Pedro de Atacama, 2013, № 45, p. 41-54. http://revistas.ucn.cl/ index.php/estudios-atacamenos/article/view/56

CORREA, V \& VIDAL, D. Geografía de la crisis del cuidado en Santiago: una aproximación centrada en la demanda de mano de obra extranjera. En: CORREA, V; BORTOLOTTO, I y MUSSET, A. (eds.), 
Geografías de la espera. Migrar, habitar y trabajar en la ciudad de Santiago, Chile 1990-2012. Santiago: Uqbar, 2013, p. 285-310.

DEPARTAMENTO DE EXTRANJERÍA Y MIGRACIÓN DEL MINISTERIO DEL INTERIOR DE CHILE (DEM). Informe anual de Extranjería y Migración. Santiago: Ministerio del Interior de Chile, 2010.

DILLEHAY, T \& NÚÑEZ, L. Camelids, caravans, and complex societies in the south-central Andes. En SAUNDERNS, N; MONTMOLLIN,O. (eds.). Recent studies in pre-Columbian archaeology. Oxford: BAR International, 1988, p. 603-634.

ENCUESTA DE CARACTERIZACIÓN SOCIOECONÓMICA NACIONAL (CASEN) . Síntesis de resultados. Santiago: Ministerio de Desarrollo Social, 2013.

ENCUESTA DE CARACTERIZACIÓN SOCIOECONÓMICA NACIONAL (CASEN). Síntesis de resultados. Santiago: Ministerio de Desarrollo Social, 2015.

FERRO, S. Aportes de la Economía del Cuidado para un sistema público de cuidados en América Latina. En FERRO, S.; VIEIRA, T (orgs.). Mulheres Entre Fronteiras. Olhares Interdisciplinares Desde O Sul. Foz de Iguazú: Ediunila, 2019, p. 110-146.

GARCÉS, A \& MORAGA, J. Poder transportista. Nuevos liderazgos aymara en la frontera de Bolivia y Chile. Antropologías del Sur, Santiago, 2018, Vol. 5, № 10, p. 39-54. https://dialnet.unirioja.es/ servlet/articulo?codigo $=6756895$

GARCÉS, A; MORAGA, J \& MAUREIRA, M. Tres movilidades para una ruta: Espacio, comercio y transnacionalidad boliviana en Tarapacá. Estudios Atacameños, San Pedro de Atacama, 2016, Vol.5, Nㅜ 3, p. 205-220. https://scielo.conicyt.cl/scielo.php?script=sci_arttext\&pid=S0718-10432016000200011

GARGALLO, F. Las diversas teorías y prácticas feministas de mujeres indígenas. Tunja: Universidad Tecnológica y Pedagógica de Colombia, 2012.

GAUTIER, A. Mujeres y colonialismo. En: FERRO, M. (ed.). El libro negro del colonialismo. Siglos XVI al XXI: Del exterminio al arrepentimiento. Madrid: La Espera, 2005, p. 677-723.

GAVILÁN, V. Buscando vida: Hacia una teoría aymara de la división del trabajo por género. Chungará, 2002, Vol.34, N 1, p. 101-117. http://dx.doi.org/10.4067/S0717-73562002000100006.

GAVILÁN, V. Representaciones del cuerpo e identidad de género y étnica en la población indígena del norte de Chile. Estudios Atacameños, 2005, №30, p. 135-148. http://dx.doi.org/10.4067/ S0718-10432005000200008.

GILL, L. Creating citizens, making men: the military and masculinity in Bolivia. Cultural Anthropology, 1997, Vol. 12, N 4, p.527-550. DOI: 10.1525/can.1997.12.4.527

GONZÁLEZ, H Características de la Inserción de Aymaras Chilenos y Bolivianos en el Área de Arica. Arica: Taller de Estudios Andinos, 1998. 
GONZÁLEZ, S. Arica y la triple frontera, Integración y Conflicto entre Bolivia, Perú y Chile. Iquique: Aríbalo Ediciones, 2006.

GONZÁLEZ, S. El Norte Grande de Chile y sus dos Triple-Fronteras: Andina (Perú, Bolivia y Chile) y Circumpuneña (Bolivia, Argentina y Chile). Cuadernos interculturales, Viña del Mar, 2019, Vol. 7, N 13, p. 27-42. http://www.redalyc.org/pdf/552/55212234003.pdf

GONZÁLEZ, S. La voz desde lejos. La Triple-Frontera Andina: entre la heterología y la globalización. Andamios, México, 2015, Vol. 12, № 28, p. 19-41. https://dialnet.unirioja.es/servlet/articulo?codigo $=5498205$

GONZÁLVEZ, H. Los cuidados en la migración transnacional. Una categoría de análisis social y política. Sur. Revista Internacional de Derechos Humanos, 2017, Vol.13, N²4, p.43-52. https://sur. conectas.org/wp-content/uploads/2017/02/4-sur-24-esp-herminia-gonzalvez-torralbo.pdf

GONZÁLVEZ, H \& ACOSTA, E. Cruzar las Fronteras de los cuidados. La migracion transnacional más allá de las dicotomías analíticas. En: GUIZARDI, M (ed.). Las Fronteras del Transnacionalismo. Limites y desbordesde de la experiencia migrante en el centro y norte de Chile.Santiago: Ocho Libros, 2015, p. 126-149.

GUIZARDI, M \& GARCÉS, A. Mujeres peruanas en las regiones del Norte de Chile: Apuntes preliminares para la investigación. Revista de Estudios Atacameños, 2012, Vol. 44, p. 5-34. http://dx.doi. org/10.4067/S0718-10432012000200002

GUIZARDI, M \& GARCÉS, A. Circuitos migrantes. Itinerarios y formación de redes migratorias entre Perú, Bolivia, Chile y Argentina en el norte grande chileno. Papeles de Población,Toluca, 2013, Vol. 19, № 78, p. 65-110. https://dialnet.unirioja.es/servlet/articulo?codigo=5345290

GUIZARDI, M; HEREDIA, O; MUÑOZ, A; DÁVILA, G \& VALDEBENITO, F. Experiencia migrante y apropiaciones espaciales: una etnografía visual en las inmediaciones del Terminal Internacional de Arica (Chile). Revista de Estudios Sociales, 2014, Vol. 48, p. 166-175. https://doi.org/10.7440/ res48.2014.13

GUIZARDI, M; VALDEBENITO, F: LÓPEZ, E \& NAZAL, E. Hyper-Border Space: Peruvian Migrants In The Arica Terminal (Chile). Revista Migraciones Internacionales, 2017, Vol. 9, № 1, p.151-178.https:// www.redalyc.org/pdf/151/15149956006.pdf

GUIZARDI, M.; VALDEBENITO, F.; LÓPEZ, E. \& NAZAL, E. Des/Venturas De La Frontera. Una Etnografía Sobre Las Mujeres Peruanas Entre Chile Y Perú. Santiago: Uah, 2019.

GUNDERMANN, H. Procesos regionales y poblaciones indígenas en el norte de Chile. Un esquema de análisis con base en la continuidad y los cambios de la comunidad andina1. Estudios Atacameños, San Pedro de Atacama, 2001, Vol. 21, p. 89-112. https://doi.org/10.22199/ S07181043.2001.0021.00005 
GUNDERMANN, H \& GONZÁLEZ, H. Pautas de integración regional, migración, movilidad y redes sociales en los pueblos indígenas de Chile. Universum, 2008, Vol.23, № 1, p. 82-115. http://dx.doi. org/10.4067/S0718-23762008000100006

GUNDERMANN, H \& VERGARA, J. I. Comunidad, organización y complejidad social andinas en el norte de Chile. Estudios atacameños, San Pedro de Atacama, 2009, Vol. 38, p.107-126.http://dx. doi.org/10.4067/S0718-10432009000200008

HOCHSCHILD, A. Las cadenas globales de afecto y asistencia y la plusvalía emocional. En: GIDDENS A.; HUTTON, W. (eds.). El límite: la vida en el capitalismo global, Barcelona: Tusquets, 2001, p. 187-209.

HOLAHAN, D. El uso de minas terrestres en Chile. Hacia una teoría de la frontera militar. Civitas, 2005, Vol.5, N², p. 343-351. http://www.redalyc.org/articulo.oa?id=74250207

INSTITUTO NACIONAL DE ESTADÍSTICAS DE CHILE (INE). Características sociodemográficas de la inmigración internacional en Chile Censo 2017. Santiago: INE, 2018.

KOVIC, C; KELLY, P \& MELGAR, L. Fronteras seguras, cuerpos vulnerables: migración y género en la frontera sur. Debate Feminista, México, 2006, Vol. 33, № 1, p. 69-83. http://desde-elmargen.net/ fronteras-migracion-y-genero-reflexiones-desde-el-feminismo-fronterizo/

LARRAíN, P. Mujeres tras las huellas de los soldados. Revista de Historia, Santiago, 2000, Vol.33, p 227-261. http://dx.doi.org/10.4067/S0717-71942000003300005.

LARSON, B. Andean Communities, Political Cultures, and Markets: The Changing Contours of a Field. En: HARRIS, O.; TANDETER, E. (eds.). Ethnicity, markets, and migration in the Andes: at the crossroads of history and anthropology. Durham: Duke University Press, 1995, p. 5-54.

LEIVA, S. Organización social del cuidado en Bolivia y Chile: Estado y cuidadanía. Revista Austral de Ciencias Sociales, 2015, N²8, p. 61-81. http://www.redalyc.org/articulo.oa?id=45955899004

LEIVA, S \& COMELÍN, A. Cadenas globales de cuidado entre chile y bolivia y migración circular. En: BERRIOS J.; BORTOLOTTO, I (eds.). Migración e Interculturalidad: Perspectivas Contemporáneas en el Abordaje de la Movilidad Humana. Santiago: Editorial San Pablo, 2017, p. 180-213.

LEIVA, S; MANSILLA, M.Á \& COMELIN, A. Condiciones laborales de migrantes bolivianas que realizan trabajo de cuidado en Iquique. Si Somos Americanos, 2017, Vol. 17, N 1, p.11-37. http://dx.doi. org/10.4067/S0719-09482017000100011

LEIVA, S \& ROSS, C. Migración circular y trabajo de cuidado: Fragmentación de trayectorias laborales de migrantes bolivianas en Tarapacá. Psicoperspectivas, Valparaíso, 2016, Vol. 15, №3, p. 56-66. https://doi.org/10.5027/psicoperspectivas-vol15-issue3-fulltext-770

LÉVI-STRAUSS, C. Estructuras elementales del parentesco. Barcelona: Paidós, 1969. 
LIBERONA, N. De las fronteras geopolíticas a las fronteras sociales: La migración boliviana a través de la prensa de Tarapacá (1990-2007). Estudios fronterizos, 2015, Vol.16, № 32, p. 41-74.: http:// www.scielo.org.mx/scielo.php?script=sci_arttext\&pid=S0187-69612015000200002

MANGAN, J. Trading Roles: Gender, Ethnicity, and the Urban Economy in Colonial Potosí. Durham: Duke University Press, 2005.

MARGARIT, D., IMILAN, W., \& GRAU M. O. (2019). Migraciones actuales en magallanes: caracterización y trayectorias de nuevos procesos migratorios. Magallania, 2019, Vol. 47, №2, p. 73-92 http:// www.magallania.cl/index.php/magallania/article/view/1150

MARTíNEZ, J. El mapa migratorio de América Latina y el Caribe, las mujeres y el género. Santiago: CEPAL, 2003.

MARTÍNEZ, J \& SOFFIA, M. Una aproximación descriptiva y Sociodemográfica de las mujeres inmigrantes en Santiago de Chile, desde el registro de ciami. En: CORREA, V.; BORTOLOTTO, I \& MUSSET, A (eds.). Geografías de la espera. Migrar, habitar y trabajar en la ciudad de Santiago, Chile. 1990-2012.Santiago de Chile: Uqbar editors, 2013, p. 63-95.

MATTINGLY, D. The home and the world: domestic service and international networks of caring labor. Annals of the Association of American Geographers, 2011, Vol. 91, № 2, p. 370-386. https:// doi.org/10.1111/0004-5608.00249

MCEVOY, C. Guerreros y civilizadores. Política, sociedad y cultura en Chile durante la Guerra del Pacífico. Santiago: Ediciones UDP, 2011.

MEENTZEN, A. Relaciones de género, poder e identidad femenina en cambio. El orden social de los aymaras rurales peruanos desde la perspectiva femenina. Cuzco: Centro Bartolomé Las Casas/ Deutscher Entwicklungsdients, 2007.

MÉNDEZ, C. "Incas sí, indios no". Apuntes para el estudio del nacionalismo criollo en el Perú. Lima: IEP, 1995.

NOVICK, S. Migraciones y Mercosur: una relación inconclusa. Catálogos UBA, Buenos Aires, 2010

PATEMAN, C. (1995). El contrato sexual. Barcelona: Anthropos, 1995.

PÉREZ, C; GUIZARDI, M; VICUÑA, T \& ROJAS, T. Del contexto fronterizo y migratorio. En VICUÑA, T.; ROJAS, T. (eds.) Migración internacional en Arica y Parinacota: Panoramas y tendencias de una región fronteriza, Santiago: Editorial de la Universidad Alberto Hurtado, 2015, p. 49-70.

PISANI, M \& YOSKOWITZ, D. The maid trade: Cross-border work in South Texas. Social Science Quarterly, 2002, Vol. 83, Nº 2, p. 568-579. http://dx.doi.org/10.1111/1540-6237.00101

PODESTÁ, J. Regiones fronterizas y flujos culturales: La peruanidad en una región chilena. Revista Universum, 2011, Vol.1, N²6, p. 123-137. http://dx.doi.org/10.4067/S0718-23762011000100008. 
PREMO, B. From the pockets of women: the gendering of the mita, migration and tribute in colonial Chucuito, Peru. The Americas, Cambridge, 2000, Vol.57, No 1, p.63-93. https://www.jstor.org/ stable/1007712

RAMOS, R. \& URBINA, D. Percepción de las mujeres in Migrantes usuarias de la pastoral de migraciones Incami-lquique en cuanto a su vinculación con las redes de apoyo en la región de Tarapacá durante el segundo semestre del año 2011. Disertación (Tesis de Pregrado). Universidad Arturo Prat, Iquique, 2012.

RIVERA, S. Bircholas: trabajo de mujeres. Explotación capitalista y opresión colonial entre las migrantes aymaras de La Paz y El Alto, Bolivia. La Paz: Editorial Mama Huaco, 1996.

ROJAS, N; AMODE, N; KOECHLIN, J \& JIMÉNEZ, R. Migraciones en la triple frontera andina: Bolivia, Chile y Perú. Desafíos persistentes y oportunidades estructurales. En: Observatorio Iberoamericano sobre Movilidad Humana, Migraciones y Desarrollo (coord.). Las migraciones en las fronteras en Iberoamérica, Madrid: OBIMID, 2016, p. 61-86.

ROJAS, N \& BUENO, S. Redes de inclusión. Estudios sociolaborales de migrantes en Arica. En: ROJAS, N.; VICUÑA, T. (eds.). Migración y Trabajo. Estudio y propuestas para la inclusión sociolaboral de migrantes en Arica. Santiago: OIM-Ciudadano Global, 2014, p. 56-100.

ROJAS, N \& SILVA, C. La migración en Chile: breve reporte y caracterización. Madrid: OBIMID, 2016.

ROUVIĖRE, L. Gobernar territorialidades transfronterizas. Seguridad y "desarrollo con identidad" aymara en la triple frontera del norte de Chile (Chile-Perú-Bolivia). Trace. Travaux et recherches dans les Amériques du Centre, 2014, № 65, p.37-50.

RYBURN, M. Living the Chilean dream? Bolivian migrants' incorporation in the space of economic citizenship. Geoforum, 2016a, Vol.76, p. 48-58. http://doi.org/10.1016/J.GEOFORUM.2016.08.006

RYBURN, M. Living the uncertain citizenship: everyday practices of Bolivian migrants in Chile. Disertación (Tesis doctoral) Queen Mary University, Londres: Reino Unido, 2016b.

SATER, W. Andean tragedy: fighting the war of the Pacific, 1879-1884. Nebraska: University of Nebraska Press, 2007.

SEGATO, R. Las estructuras elementales de la violencia. Ensayos sobre género entre la antropología, psicionálisis y los derechos humanos. Buenos Aires: Prometeo, 2010.

SEGATO, R. La crítica de la colonialidad en ocho ensayos. Y una antropología por demanda. Buenos Aires: Prometeo, 2013.

SEMPAT, C. Exchange in the Ethnic Territories between 1530 and 1567: The Visitas of Huanuco and Chucuito. En: HARRIS, O.; TANDETER, E (eds.). Ethnicity, markets, and migration in the Andes: at the crossroads of history and anthropology, Durham: Duke University Press, 1995, p. 101-134. 
STERN, S. The Variety and Ambiguity of Native Andean Intervention in European Colonial Markets. En: HARRIS, O.; TANDETER, E. (eds.). Ethnicity, markets, and migration in the Andes: at the crossroads of history and anthropology. Durham: Duke University Press, 1995, p. 73-100.

ST JOHN, R. The Bolivia-Chile-Peru Dispute in the Atacama Desert. Boundary \& Territory Briefings, Boundary and Territory Briefing. 1994, Vol.1, № 6, p.1-32.

TAPIA, M. Frontera y migración en el norte de a partir del análisis de los censos población: Siglos XIX-XXI. Revista de geografía Norte Grande, 2012, N 53, p.177-198. http://dx.doi.org/10.4067/ S0718-34022012000300011

TAPIA, M. Extranjeros fronterizos en las regiones extremas de Chile: entre migración y circulación. 1990-2014. En: ROJAS, T.; VICUÑA, T. (eds.), Migración y Trabajo. Estudio y propuestas para la inclusión sociolaboral de migrantes en Arica. Santiago: OIM-Ciudadano Global, 2014, p. 31-55.

TAPIA, M. Frontera, movilidad y circulación reciente de peruanos y bolivianos en el norte de Chile. Estudios atacameños, 2015, N 50, p. 195-213. http://dx.doi.org/10.4067/S0718-10432015000100010

TAPIA, M \& CHACÓN, F. Vínculos transfronterizos: vida, movilidad y comercio en el Barrio Boliviano de Iquique, Chile REMHU, Revista Interdisciplinar de la Movilidad Humana, Brasilia, 2016, Vol. 24, N 47, p. 131-152. http://dx.doi.org/10.1590/1980-85852503880004709.

TAPIA, M \& GAVILÁN, V. Diagnóstico de las migraciones fronterizas de la I Región de Tarapacá, Chile. Iquique: Universidad Arturo Prat, 2006.

TAPIA, M; LIBERONA, N \& CONTRERAS, Y. El surgimiento de un territorio circulatorio en la frontera chileno-peruana: estudio de las prácticas socioespaciales fronterizas. Revista de Geografía Norte Grande, Santiago, 2017 № 66, p. 117-141. http://dx.doi.org/10.4067/S0718-34022017000100008

TAPIA, M \& RAMOS, R. Mujeres migrantes fronterizas en Tarapacá a principio del siglo XXI. El cruce de las fronteras y las redes de apoyo. Polis, Santiago. 2013, Vol.12, № 35, p. 229-257. http://dx.doi. org/10.4067/S0718-65682013000200011

TUNG, T. Life on the move: bioarchaeological contributions to the study of migration and diaspora communities in the Andes. En SILVERMAN, H; ISBELL, W (eds.) The Handbook of South American Archaeology New York: Springer, 2008, p. 671-680.

VALDEBENITO, F \& GUIZARDI, M. Las fronteras de la modernidad. El espacio Tacnoariqueño y la nacionalización del Norte Grande chileno (1883-1929). Revista de Estudos Ibero-americanos (PUC-RS, Brasil), 2015, Vol. 40, N², p. 277-303. http://www.redalyc.org/articulo.oa?id=1346/134635319006

VICH, V. El discurso sobre la sierra del Perú: la fantasía del atraso. Critica y Emancipacion, 2010. Vol. 3, p. 155-68. http://biblioteca.clacso.edu.ar/ojs/index.php/critica/article/view/171

VITALE, L. Interpretación marxista de la historia de Chile. Santiago: LOM, 2011. 
WOO, O. Abuso y violencia a las mujeres migrantes. Abuso y violencia a las mujeres migrantes. En: FERNADEZ, T (ed.). Violencia contra la mujer en México. Ciudad de México: Comisión Nacional de Derechos Humano/Universidad Nacional Autónoma de México, 2004.

ZAPATA, P, FERNÁNDEZ, P \& SÁNCHEZ, M. C. Violencia de género en mujeres con ascendencia étnica aymara en el extremo norte de Chile. Revista de Psiquiatría y Salud Mental, 2012, Vol. 5, No 3, p. 167-172. https://doi.org/10.1016/j.rpsm.2012.02.003 